\title{
Intrauterine exposure to $17 \beta$-oestradiol (E2) impairs postnatal development in both female and male prostate in gerbil
}

\author{
Bruno D.A. Sanches ${ }^{a}$, Juliana M. Santos ${ }^{a}$, Bruno C. Zani ${ }^{a}$, Manoel F. Biancardi ${ }^{b}$, \\ Fernanda C.A. Santos ${ }^{\mathrm{b}}$, Rejane M. Góes ${ }^{\mathrm{c}}$, Patricia S.L. Vilamaior ${ }^{\mathrm{c}}$, Sebastião R. Taboga ${ }^{\mathrm{c}, *}$ \\ a State University of Campinas - UNICAMP, Department of Structural and Functional Biology, Bertrand Russel Av., s/n, Campinas, São Paulo, Brazil \\ ${ }^{\mathrm{b}}$ Federal University of Goiás - UFG, Department of Histology, Embryology and Cell Biology, Samambaia II, Goiânia, Goiás 74001970, Brazil \\ c Univ. Estadual Paulista - UNESP, Department of Biology, Laboratory of Microscopy and Microanalysis, Cristóvão Colombo St., São José do Rio Preto, São \\ Paulo, Brazil
}

\section{A R T I C L E I N F O}

\section{Article history:}

Received 6 December 2016

Received in revised form 19 July 2017

Accepted 20 July 2017

Available online 30 July 2017

\section{Keywords:}

Female prostate

Intrauterine exposure

E2

Environment

ESR1

ESR2

AR

TGF $\beta 1$

FGF10

CD34

Sex variations

\begin{abstract}
A B S T R A C T
We employed histological techniques to assess the effects of intrauterine exposure to different dosages of E2 on male and female Mongolian gerbils on the postnatal development of the prostate. E2 promotes alterations this gland branches in the female, but not in males, even at low dosage, at higher dosages, acini of altered aspect are verified in the male and female prostate, as well as a decrease in branching number, reduced cell proliferation and staining for FGF10, simultaneously to the increased labelling for TGF $\beta 1$, which may account for alterations on branching of the prostate. The sensitivity of the female prostate to intrauterine exposure to E2, which can reflect the E2 dependence of female prostate development. This becomes alarming in view of the occurrence of prostate in female of several mammals and including women, and the possibility that low E2 dosage exposures considered safe to males provoke developmental alterations in female prostate.
\end{abstract}

(c) 2017 Elsevier Inc. All rights reserved.

\section{Introduction}

Since the 1990 s, a series of studies on the effects of endocrine disruptors (ED) has been carried out; such compounds have attracted growing interest because of the potential to provoke alterations in the endocrine system of several species, including humans [1], resulting in profound physiological effects, affecting the reproduction of the species and their behaviour. In the case of humans, concerns are raised about the teratogenicity of some compounds, as well as increased susceptibility to pathological conditions, notably in the mammary glands, thyroid, cardiovascular system, nervous system and prostate [2-4]. In addition, the presence of steroids can also generate environmental concern due to the high affinity of these compounds for steroid receptors, and the presence of very

\footnotetext{
* Corresponding author at: Department of Biology, Laboratory of Microscopy and Microanalysis, São Paulo State University, 2265, Cristóvão Colombo Street, Jardim Nazareth, São José do Rio Preto, São Paulo 15054-000, Brazil.

E-mail address: taboga@ibilce.unesp.br (S.R. Taboga).
}

few studies on this subject as well as the effect of these hormones at low concentrations [1,5-7].

Oestradiol (E2) concentrations present in sewage and soil vary greatly between countries [1], and between different treatment systems [8]. Despite advances in the removal of hormones, even in developed countries, the presence of active E2 has been reported in treated water [5]. More worrying still is the presence of E2 in soil due to livestock activity, but data in this regard are scarce, making it difficult to assess the effects of oestradiol present in animal waste [1].

Intrauterine exposure to oestrogen causes major alterations in the development of various organs, such as the mammary glands [9], testis [10] and prostate [11-13]. The prostate develops through epithelial-mesenchymal interactions between the urogenital sinus epithelium (UGE) and urogenital sinus mesenchymes (UGM) in budding processes, and, at the same time, the budding branch in inductive mesenchymes surrounding the UGM finally differentiate into prostatic acini and ducts [14-19,65]. Intrauterine oestrogenisation affects budding morphogenesis, causing hypomorphia 
$[13,20,21]$, as well as increasing prostate susceptibility to tumorigenesis with senescence $[4,12,22]$. Furthermore, such exposure is also associated to changes in the prostate branching phase [13,23].

Despite the importance of the subject, there are few studies on the effects of environmentally relevant doses of E2 on prostate development, and on the effects of such exposure on the female prostate. The Mongolian gerbil is a promising species for carrying out this type of study, since the occurrence of prostate in females is almost ubiquitous [18,24-28]. This study demonstrates the presence of morphological alterations in the Mongolian gerbil prostate due to intrauterine exposure to environmentally relevant E2 dosage and demonstrates the worsening of them due to a higher dosage, and investigates some possible sources of these morphological alterations.

\section{Material and methods}

\subsection{Experimental design}

The animals used in this study were provided by the São Paulo State University (UNESP, São José do Rio Preto), kept in plastic cages under controlled conditions of light ( $12 \mathrm{~h}$ light/12 h dark) and temperature $\left(25^{\circ} \mathrm{C}\right)$ and provided with water filtered and feed with rodent food ad libitum (Presence, Labina-Purina ${ }^{\circledR}$, composition: $23 \%$ proteins, $4 \%$ fats, $5 \%$ fibers and $12 \%$ minerals). The handling of animals and the experiments were conducted following the ethical guidelines of UNESP (CEUA - 116/2015), which follow the Guide for Care and Use of Laboratory Animals. We used 20 adult females and 20 adult male Mongolian gerbils (between 3 and 6 months of age) which were arranged randomly to form couples. By means of these couples, 4 experimental groups were formed so that each group consisted of five couples and 12 pups from each group were derived from these couples, 6 of each sex. In order to test whether environmentally relevant doses of E2 could impact on the development of the prostate in females and males at the beginning of its functional differentiation at P30, with "P" indicating the post-natal period, during that period, five pregnant females were subjected to doses of $500 \mathrm{ngBW} / \mathrm{D}$ of $17 \beta$-oestradiol ( $\beta$-oestradiol, SigmaAldrich) diluted in $100 \mu \mathrm{l}$ of mineral oil (Nujol Mantecorp); this was considered low [29], from the 16th day of gestation to the day before birth, the 24th day, to cover the intrauterine prostate development period. Later, 6 pups of both sexes were sacrificed at P30, to form the experimental group treated with a low dose of oestradiol. Another five pregnant females were dosed with $100 \mu \mathrm{l}$ of mineral oil (Nujol Mantecorp) and their pups were sacrificed at P30 to form the P30 control group.

In order to investigate the intrauterine oestrogenisation of the gland on branching process, another 5 pregnant females were subjected to concentrations of oestradiol considered high [29], $500 \mu \mathrm{g} . \mathrm{BW} /$ day of $17 \beta$-oestradiol ( $\beta$-oestradiol, Sigma-Aldrich) diluted in $100 \mu \mathrm{l}$ of mineral oil (Nujol Mantecorp) from the 16th day of gestation to the day before birth, the 24th day, to cover intrauterine development period of the prostate. Six pups of each sex were sacrificed at P14, the period of intense branching gland, in order to compose the group treated with a high dose of E2; finally, another 5 pregnant females were dosed with $100 \mu$ l of mineral oil (Nujol Mantecorp) and 6 pups of each sex were used to compose the P14 control group. The animals were sacrificed by lethal injection containing a mixture of an anaesthetic Ketamine $(100 \mathrm{mg} / \mathrm{kg}$ bw, Dopalen, Vetbrands, Brazil), and a muscle relaxant, xylazine (11 mg/kg bw Rompun, Bayer, Brazil); the blood was taken for serum oestradiol dosage and prostate complexes were extracted, fixed and then subjected to immunohistochemical assays.

\subsection{Light microscopy}

The gerbil prostatic complexes were fixed for $24 \mathrm{~h}$ in $4 \%$ paraformaldehyde or Metacarn (ratio 6: 3: 1 mixture of methanol, chloroform and acetic acid, respectively), and were dehydrated in ethanol series, cleared in xylene, and finally embedded in paraffin (Histosec, Merck Dermstadt, Germany). Prostatic complexes in $4 \%$ paraformaldehyde were sent for immunohistochemical assays for PCNA, ER $\alpha, E R \beta, A R$ and p63, in addition to immunofluorescence assays for FGF10, TGF $\beta 1$ and CD34. Already, those included in Metacarn were subjected to staining with haematoxylin-eosin (H\&E) for morphological and 3D reconstruction analysis. All prostate complexes were cut serially $(5 \mu \mathrm{m})$ on a microtome and histological slides were mounted. Image capture was performed using an Olympus BX60 light microscope (Olympus, Japan) attached to a computer with DP-BSW V3.1 software (Olympus) and AMS Image-Pro 6.1 software (Media Cybernetics) for Windows (Media Cybernetics, Silver Spring, MD).

\subsection{Three-dimensional reconstructions}

Three-dimensional reconstructions were performed for all experimental groups to obtain a 3D detailing of branching and morphofunctional differentiation of the gerbil ventral prostate in males or the single prostatic lobe in females and the effects of oestradiol on such processes. Histological sections of the prostatic complex were cut serially, $5 \mu \mathrm{m}$ thick, and were then mounted in histological slides and stained with H\&E. After, these were analysed and photographed through an Olympus BX60 light microscope (Olympus, Japan) coupled to a computer with the DP-BSW V3.1 software (Olympus) AMS and Image-Pro 6.1 software (Media Cybernetics) for Windows (Media Cybernetics, Silver Spring, MD). Later, the images were reconstructed through Reconstruct software [30]. The number of prostatic branches was obtained through this software, so that all branches of the ventral prostate were rebuilt for each animal of each experimental group ( $n=3$ per experimental group).

\subsection{Immunohistochemistry}

The sections of gerbil ventral prostates of males and of the single prostatic lobe of females were subjected to immunohistochemistry for the detection of PCNA, ER $\alpha, E R \beta, A R$ and p63 (As in the protocol applied to prostate described in Fochi et al., 2013). The antibodies were employed (in a dilution of 1: 100), for the detection of PCNA (mouse monoclonal IgG2a, PC10, SC- 56, Santa Cruz Biotechnology), ER $\alpha$ (rabbit polyclonal IgG, MC-20, sC-542, Santa Cruz Biotechnology), ER $\beta$ (rabbit polyclonal IgG, H-150, sc-8974, Santa Cruz Biotechnology), AR (rabbit polyclonal IgG, C-20, sc816, Santa Cruz Biotechnology, CA, USA). As a secondary antibody, PolyK4061 K4061 was employed (Dako Envision, North America, Carpinteria, USA). The incubation time was $45 \mathrm{~min}$ at $37^{\circ} \mathrm{C}$. The revelation was made through the use of diaminobenzidine (DAB) and the sections were counterstained with Harris haematoxylin. Histological sections were analysed with the Olympus BX60 light microscope (Olympus). Negative controls were obtained by omitting the step of incubating the primary antibody and the other steps are the same. Assays for PCNA, ER $\alpha, E R \beta$, AR and p63 were measured according to the methodology described hereinafter and the assays for FGF-10, TGF $\beta 1$ and CD34 were analysed qualitatively. Negative controls were obtained by omitting the step of incubating the primary antibody and the other steps are the same, as the incubation step with the rabbit anti-Mouse IgG (Post Primary, Novolink, Leica Biosystems, Buffalo Grove, IL, USA) and later with anti-rabbit Poly-HRP-IgG (Polymer, Novolink, Leica Biosystems, Buffalo Grove, IL, USA) and, finally, the revelation with DAB and counterstaining with Harris haematoxylin. Assays for PCNA, ER $\alpha, E R \beta$, AR and 
p63 were measured according to the methodology described hereinafter and the assays for FGF-10, TGF- $\beta 1$ and CD34 were analysed qualitatively.

\subsection{Quantification of immunohistochemical assays and morphometry}

For the purposes of quantification of immunohistochemical assays, the total number of cells in 30 random microscopic fields was counted for each experimental group in 3 different animals, according to the methodology described in Fochi and collaborators [31]; this was applied for PCNA, ER $\alpha, E R \beta, A R$ and p63, in order to separate the positively and negatively marked cells. A minimum of 1000 cells were counted per group and then the percentage of immunostaining was calculated as the number of positive cells divided by the total number of cells. To assess alterations in the branching process and in the development of acini, the maximum diameter [32] of all developing acini was measured in 30 random microscopic fields per animal for each group of 3 different animals. The maximum diameter of periductal smooth muscle was also measured in P14, using 30 random microscopic fields for each group of 3 different animals. Quantitative results are expressed as mean \pm standard deviation (SD).

\subsection{Immunofluorescence assays}

Immunofluorescence was performed on paraffin-embedded tissue sections using the protocol described by Lima and collaborators [33]. The prostate samples were fixed in $4 \%$ paraformaldehyde (buffered in $0.1 \mathrm{M}$ phosphate, $\mathrm{pH} 7.4$ ) for $24 \mathrm{~h}$. After fixing the tissues were washed in water, dehydrated in a series of ethanol solutions, embedded in paraffin (Histosec, Merck, Darmstadt, Germany), then sectioned to $5 \mu \mathrm{m}$ using a microtome (RM2155, Leica, Nussloch, Germany). In order to verify the effects of intrauterine exposure to E2 (500 $\mu \mathrm{g}$ BW/D) on the gland branching morphogenesis, double labelling assays for CD34 and FGF-10 were performed in histological sections of the gerbil prostate of both sexes (Polyclonal mouse CD34 IgG, B-6, sc74499 and goat polyclonal FGF-10, IgG, C-17, sc-7375, Santa Cruz Bio-technology), as well as assays for CD34/TGF- $\beta 1$ CD34 IgG; rabbit polyclonal TGF$\beta 1$ IgG, V, sc146; Santa Cruz Biotechnology), in a way that these primary antibodies were incubated overnight at a dilution of 1 : 100. The next morning, sections were incubated with goat antimouse FITC-labeled (sc-2011; Santa Cruz Biotechnology) and goat anti-rabbit Texas Red-labeled (sc-2780; Santa Cruz Biotechnology) secondary antibodies, diluted 1: 200 in 1\% bovine serum albumin (BSA) for $2 \mathrm{~h}$ at room temperature, then stained with DAPI (F36924; Life Technology, Grand Island, NY, USA). The histological sections were analysed with a ZeissImager M2 fluorescence microscope (Zeiss, Oberkochen, Germany) coupled to AxioVision (Zeiss) software. Negative controls were obtained by omitting the step of incubating the primary antibody and the other steps are the same, as the incubation step with goat anti-mouse FITC-labeled (sc-2011; Santa Cruz Biotechnology) and goat anti-rabbit Texas Red-labeled (sc-2780; Santa Cruz Biotechnology) secondary antibodies and the staining with DAPI (F36924; Life Technology, Grand Island, NY, USA).

\subsection{Statistical analysis}

Data were initially studied by analysis of variance (One-way ANOVA) and subsequently by the Tukey test for multiple comparisons, with a significance level of $5 \%(p \leq 0.05)$. Statistical tests were performed using Statistica 7.0 software (StarSoft Inc., Tulsa, OK, USA).

\subsection{Serum hormonal analysis}

The blood of male and female gerbils from the P14 experimental group was collected at the time of decapitation. The serum was centrifuged ( $3000 \mathrm{rpm}$ for $20 \mathrm{~min}$ ) and stored at $-80^{\circ} \mathrm{C}$ until analysis. Hormonal dosages were performed in duplicate by ELISA and using kits with high sensitivity (17 $\beta$-oestradiol, Cayman Chemical Company, MI, USA) following the manufacturer's instructions. The readings were performed using the lector SpectraMax Plus 384, at 405 gm (Molecular Devices, Sunnyvale, CA, USA).

\section{Results}

\section{1. $3 D$ reconstructions}

Three-dimensional reconstructions of ducts and developing prostatic acini in females showed a pattern of growth parallel to the urethral axis (Fig. 1B); this pattern is changed in females of group treated with a low dose of E2 (500 ng BW/D) on P30 in which changes in the quantity and structure of acini occur, which exhibit an altered aspect (Fig. 1D). In males treated with a low dose of E2 (500 ng BW/D) (Fig. 1F), there were no structural differences compared to the control group (Fig. $1 \mathrm{H}$ ). As for the number of branches, there was no significant difference between the group treated with a low dose of E2 (branching $1^{\text {ary }}: 15 \pm 8,2^{\text {ary }}$ : $26 \pm 2,3^{\text {ary }}: 27 \pm 7,<3^{\text {ary }}: 39 \pm 5$ ) and the control group (branching $1^{\text {ary }}$ : $16 \pm 22^{\text {ary }}: 29 \pm 5,3^{\text {ary }}: 25 \pm 2<3^{\text {ary }}: 39 \pm 4$ ) (Fig. $1 \mathrm{~J}$ ); in females, there was no significant difference for primary and tertiary branching in the group treated with E2 $(9 \pm 2,12 \pm 3$, respectively) compared to the control group $(11 \pm 2,14 \pm 5$, respectively), but a significant decrease in the number of branches in the group treated with E2 was observed for secondary branching and higher than tertiary $(9 \pm 2,24 \pm 4$, respectively) compared to the control group ( $16 \pm 2,38 \pm 4$, respectively) (Fig. $1 \mathrm{~K}$ ). Thus, these data demonstrate the susceptibility of alterations in the prostatic development in females, even due to low E2 dose exposure; thereby, the female prostate was shown to be more sensitive to intrauterine E2 exposure than the male prostate. The reconstructions of the group treated with higher doses of E2 $(500 \mu \mathrm{g})$ at P14 in males in the group treated with a high dose of E2 (Fig. 2D) verify alterations in the formation of the ductal network and partial loss of the parallel orientation of the ducts observed in the control group (Fig. 2B). In females, the formation of a network of prostatic ducts arranged parallel to the urethral axis can be observed in the control group (Fig. 2F); such an arrangement is altered in females in the group treated with a high dose of E2 and ductal and developing acini display an altered aspect (Fig. 2H). In relation to the number of branches, there was no significant difference in the primary branching, secondary and tertiary $(5 \pm 1,8 \pm 3,10 \pm 1$, respectively) compared to the control group $(7 \pm 1,13 \pm 2,14 \pm 2$, respectively); however, there was a significant reduction in the number of higher than tertiary branching in the group treated with E2 $(18 \pm 3)$ compared to the control group $(37 \pm 5)$ (Fig. $2 \mathrm{~K})$. In males treated with E2, there was no significant difference in the number of tertiary branches (18 \pm 2 ) compared to the control group (23 \pm 3 ). However, there was a reduction in the number of primary, secondary and higher than tertiary branching $(7 \pm 1,9 \pm 1,36 \pm 4$, respectively) compared to the control group $(17 \pm 2,18 \pm 2,64 \pm 5$, respectively) (Fig. 2L).

\subsection{Morphology and morphometry}

The morphological data point to the occurrence of alterations in prostate development in both males and females treated with a low dose of oestradiol (500 ng BW/D). On P30 in females, acini of 


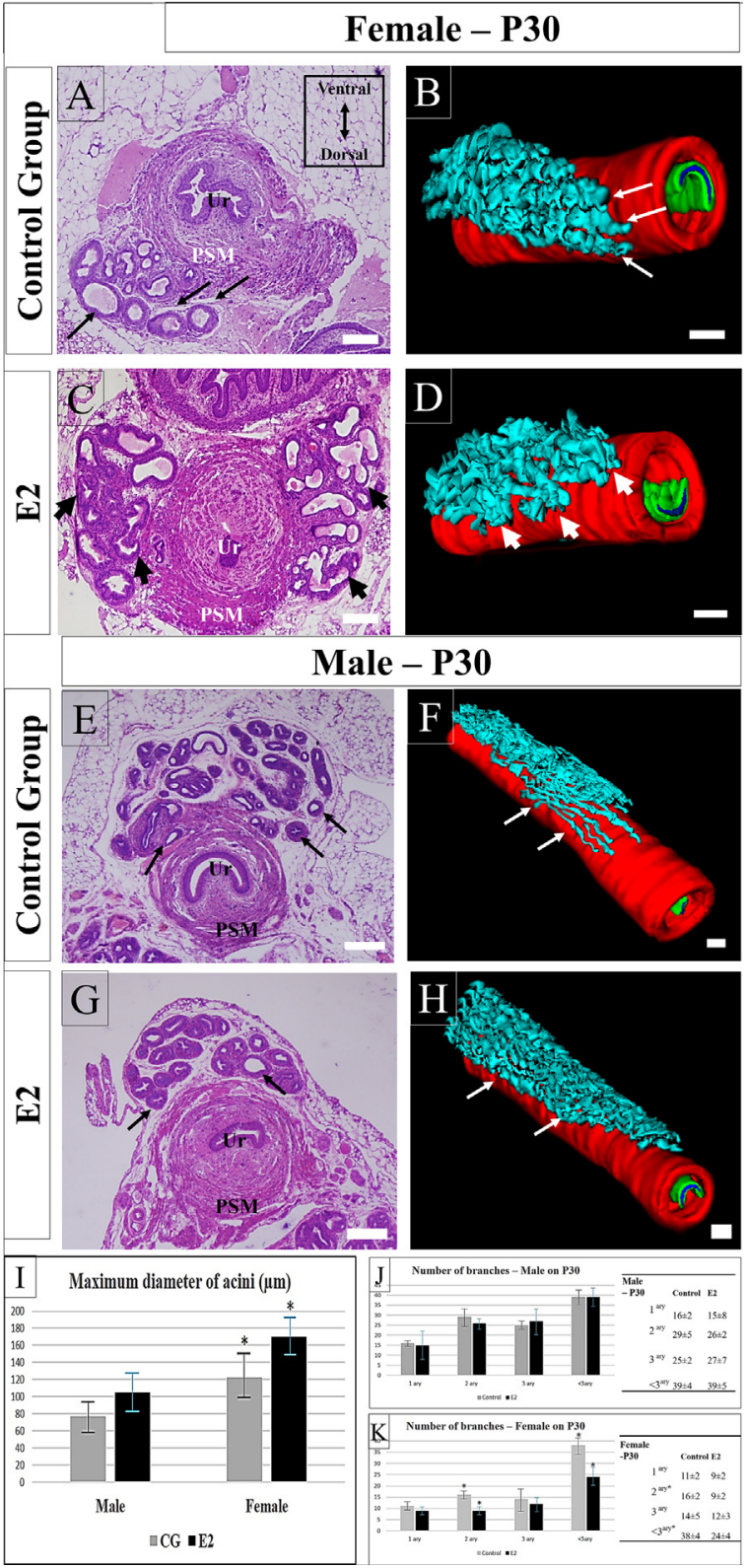

Fig. 1. Histology of the development of prostate complex and three-dimensional reconstructions of males and females on P30 in the control group and the group treated with a low dose of E2 ( $500 \mathrm{ng}$ BW/D). A, B: acini in developing control group of females demonstrating a complex three-dimensional network of ducts that run parallel to the main axis of the urethra. C, D: The E2 treated group displaying reduced branching morphogenesis and altered aspect acini. E, F: In males of the control group, there is also a network of ducts parallel to the urethra axis. G, H: In males of the treated group there are no statistically significant differences in branching number. I: The maximum diameter of acini in the female control group is greater than that seen in males, which reflects an earlier pre-maturation in females. In males and females treated with E2, the diameter of the acini becomes greater. J: There are no significant differences in the number of branches in males of the group treated with E2 compared to the control group. I: In females, there is a reduction in the number of secondary branches and higher than tertiary in the group treated with E2 compared to the control group. Ur (urethra), PSM (periurethral smooth muscle), Arrows (prostatic acini showing normal development), Arrowhead (prostate acini showing impaired development in females), Cyan (developing prostatic acini and prostatic ducts), Red (Periductal smooth muscle), Green (urethral epithelium), dark Blue (urethral lumen), Asterisk (statistically significant difference). (For interpretation of the references to colour in this figure legend, the reader is referred to the web version of this article.) an altered aspect can be observed (Fig. 1A), which is reflected in an increased maximum diameter of acini (Fig. 1I) $(169.9 \pm 27 \mu \mathrm{m})$ compared to the control group $(122.9 \pm 26 \mu \mathrm{m})$ (Fig. 1C). In males in the group treated with a low dose of E2 (500 ng BWD) at P30, there are no morphological differences (Fig. 1E) compared to the control group (Fig. 1G) and there is no difference in the maximum diameter of the acini in the treated group $(105.4 \pm 22 \mu \mathrm{m})$ compared to the control $(77.4 \pm 18 \mu \mathrm{m})$ (Fig. 1I). As for the group treated with a high dose of oestradiol ( $500 \mu \mathrm{g}$ BW/D) at P14, the occurrence of altered is observed in males of the treated group (Fig. 2C) along with a significant increase in the maximum diameter of the acini $(53.9 \pm 5 \mu \mathrm{m})$ compared to the control group $(69.6 \pm 13 \mu \mathrm{m})$ (Fig. 2A, I). In the developing female prostate, acini also present an altered aspect (Fig. 2G) compared to the control group (Fig. 2E) and the maximum mean diameter of the acini is also increased in the group treated with a high dose of oestradiol $(74.2 \pm 16 \mu \mathrm{m})$ compared to the control group $(42.8 \pm 9 \mu \mathrm{m})$ (Fig. 2I). At the same time, there was a significant increase in the maximum diameter of the smooth muscle periductal both females $(155.2 \pm 12 \mu \mathrm{m})$ and males $(172.9 \pm 16 \mu \mathrm{m})$ in the group treated with a high dose of E2 $(500 \mu \mathrm{g}$ BW/D) compared to the control group $(101.1 \pm 6,135.4 \pm 18 \mu \mathrm{m}$, respectively) (Fig. 2J).

\subsection{Immunohistochemistry assays}

Immunohistochemistry assays were performed on paraffinembedded tissue sections of high dose E2 treated gerbils $(500 \mu \mathrm{g}$ BW/D) of both sexes on P14 for the following factors:

\subsection{1. $P C N A$}

In males, at P14, PCNA has strong stromal and epithelial staining in the control group compared to the group treated with E2 (Fig. 3A, B). In females, there is also a reduction in staining for PCNA in the group treated with E2 (Fig. 3C, D). The graph demonstrates the reduction in the number of PCNA immunostained cells in the group treated with E2 in both sexes compared to the control group (Figs. 4 E, 6, Table 1, $\mathrm{p} \leq 0.05$ ).

\subsection{2. $E R \alpha$}

The staining for ER $\alpha$ at P14 seems to be more intense in males in the control group than in the treated group (Fig. 3F, G). In females, as in males, staining for the ER $\alpha$ is increased in the group treated with E2 compared to the control group (Fig. 3H, I). The graph demonstrates the increase in staining for ER $\alpha$ in the group treated with E2 in both sexes compared to the control group (Figs. $3 \mathrm{~J}, 6$, Table 1, $\mathrm{p} \leq 0.05$ ).

\subsection{3. $E R \beta$}

There is a large increase in the staining for both stromal and epithelial ER $\beta$ at P14 in treated males compared to the control group (Fig. $3 \mathrm{~K}, \mathrm{~L}$ ). In females treated with E2, as in males but less intensely, the ER $\beta$ expression is also increased in both the epithelium and in the prostatic stroma (Fig. $3 \mathrm{M}, \mathrm{N}$ ). The graphs represent the increase in the staining for the ER $\beta$ in the treated group, both for males and females in the face of the control group (Figs. 3 O, 6, Table $1, \mathrm{p} \leq 0.05$ ).

\subsection{4. $A R$}

A decrease in AR staining can be observed in both epithelium and stroma at P14 in males of the group treated with E2 (Fig. 3P, Q). In females of the group treated with E2, there is an increase in both epithelial and stromal AR staining (Fig. 3R, S). The graph demonstrates a decrease in the staining for AR in both epithelial and stromal tissue in males of the group treated with E2, while 


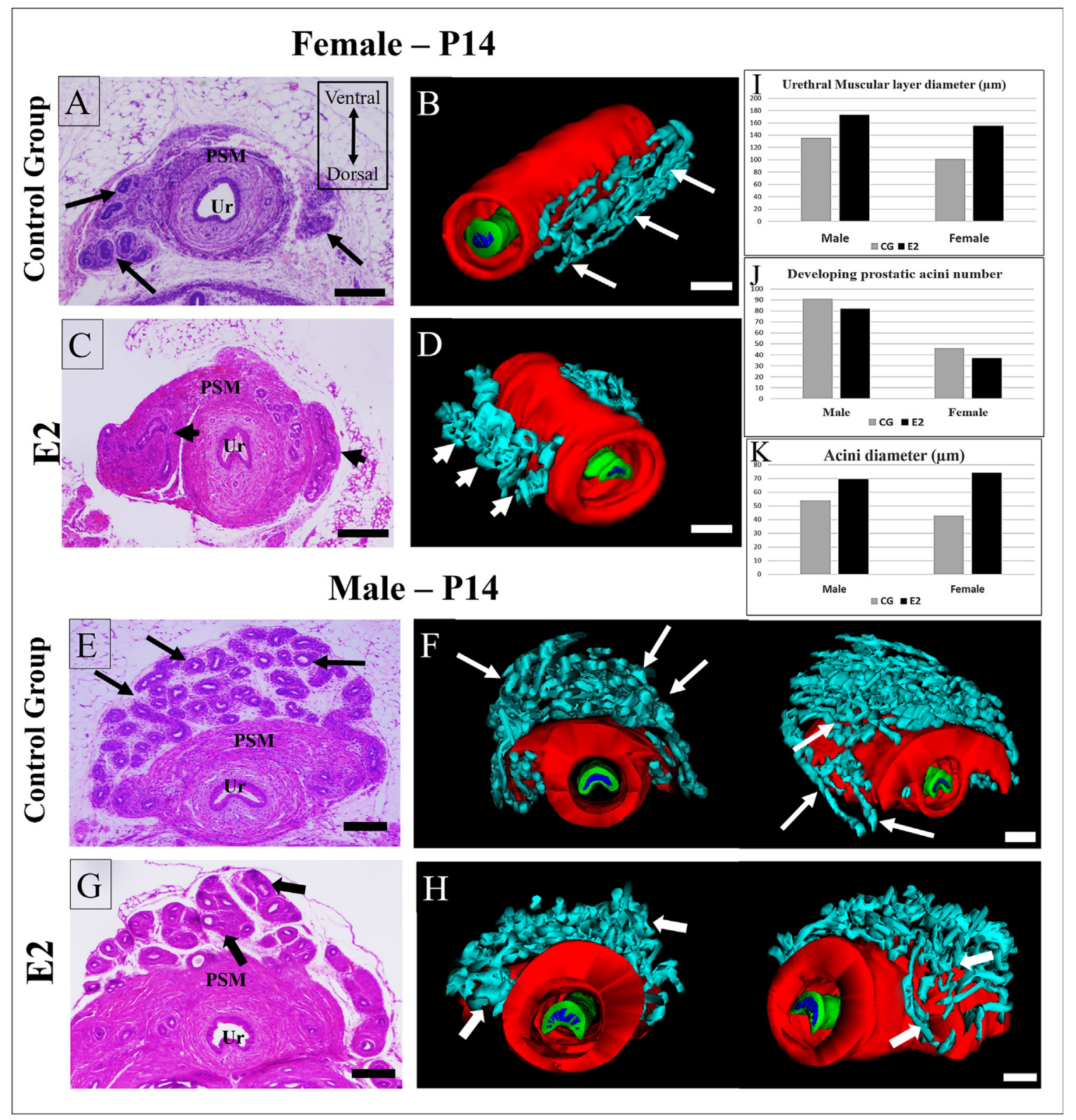

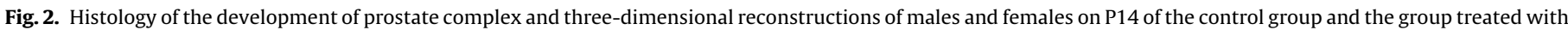

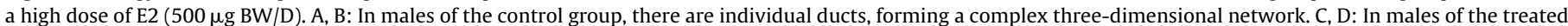

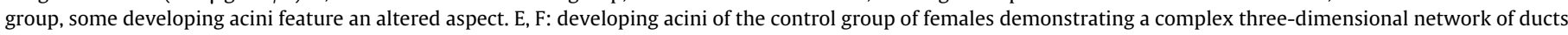

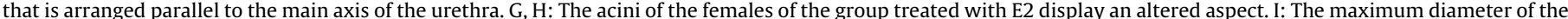

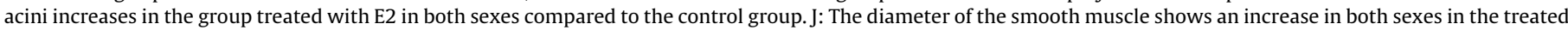

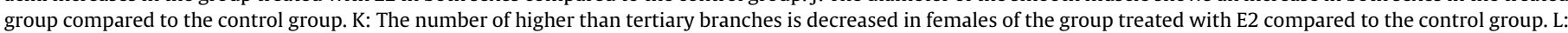

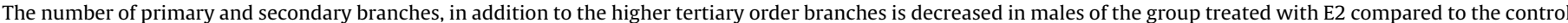

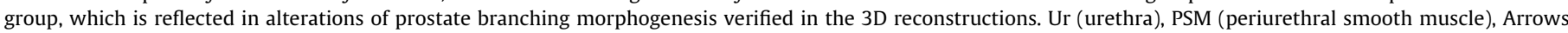

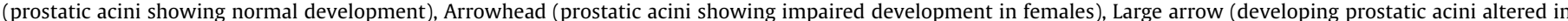

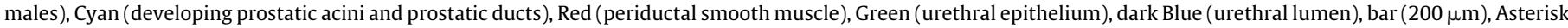
(statistically significant difference). (For interpretation of the references to colour in this figure legend, the reader is referred to the web version of this article.)

Table 1

Frequency of immunostained cells for AR, PCNA, ER $\alpha, E R \beta$ and p63 in both male and female prostate of the group treated with a high dose of E2 on P14 and in the control group. Values are expressed as mean $\pm S D(n=3) .{ }^{*}$ Significant difference between the groups $(p \leq 0.05)$.

\begin{tabular}{lllllllll}
\hline & & PCNA $^{*}$ & ER $\alpha$ & ER $\beta-$ Ep* $^{*}$ & ER $\beta-$ St* $^{*}$ & AR - Ep* $^{*}$ & AR - St* $^{*}$ & P63 \\
\hline \multirow{2}{*}{ Male } & CG & $75.4 \pm 7$ & $11.5 \pm 4$ & $7.5 \pm 2$ & $4.4 \pm 1$ & $56.2 \pm 6$ & $45.7 \pm 9$ & $40.4 \pm 9$ \\
& E2 & $42.2 \pm 16$ & $18.9 \pm 5$ & $43.2 \pm 15$ & $56.7 \pm 12$ & $32.8 \pm 4$ & $22.9 \pm 10$ \\
Female & CG & $68.9 \pm 8$ & $23.7 \pm 8$ & $52.1 \pm 15$ & $39.9 \pm 10$ & $4.2 \pm 1$ & $3.3 \pm 2$ \\
& E2 & $49.1 \pm 19$ & $36.9 \pm 11$ & $68.1 \pm 11$ & $64.1 \pm 11$ & $16.2 \pm 5$ & $8.3 \pm 3$ & $33.5 \pm 11$ \\
\hline
\end{tabular}




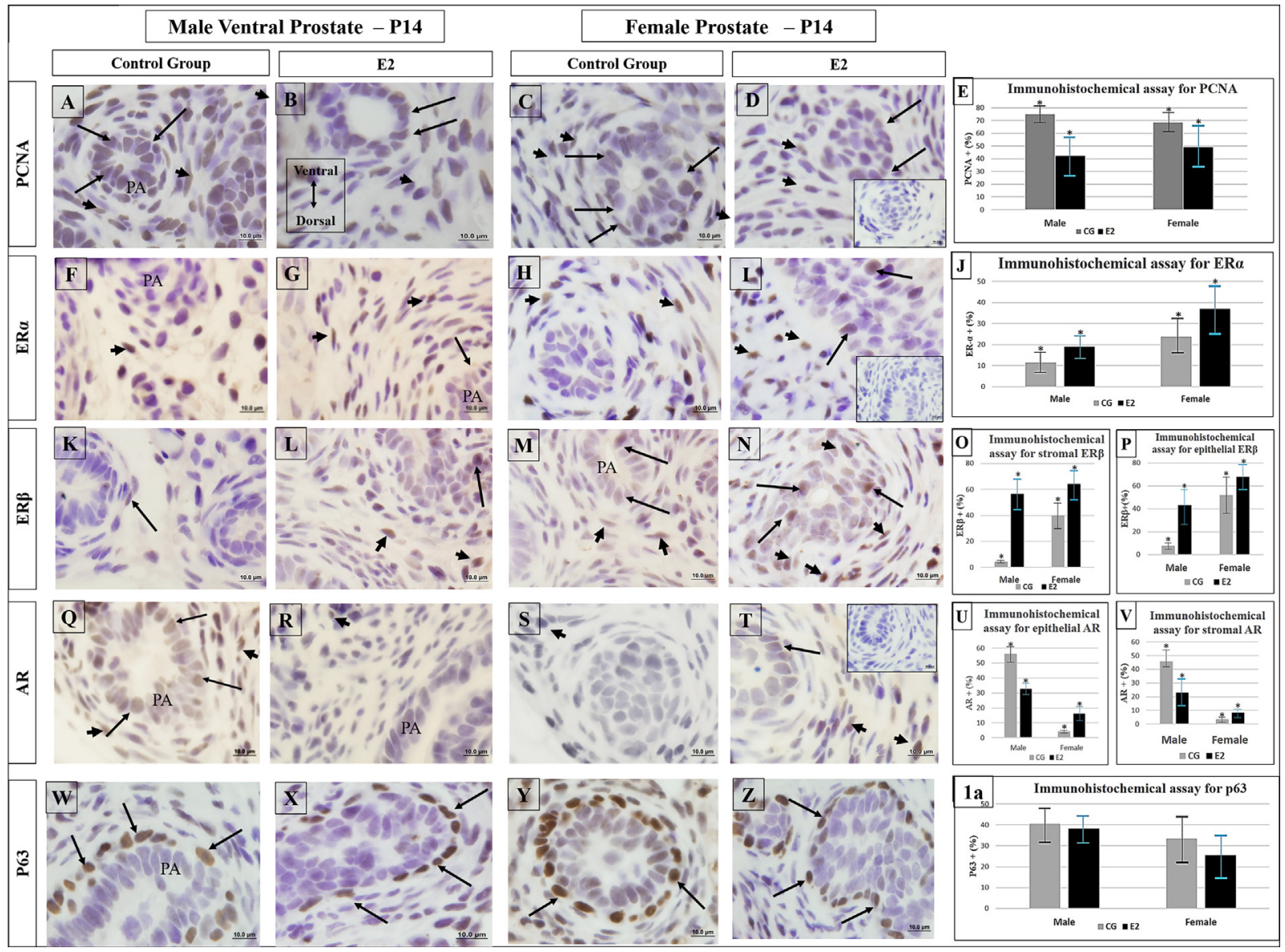

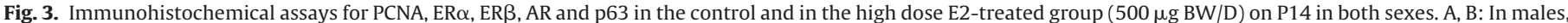

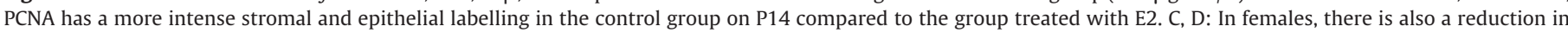

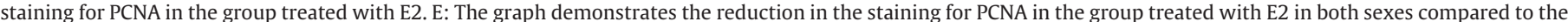

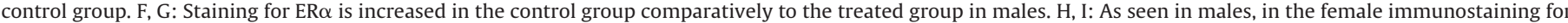

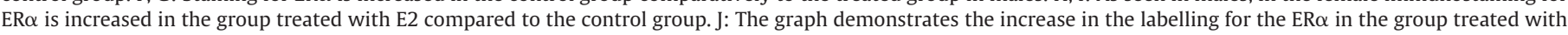

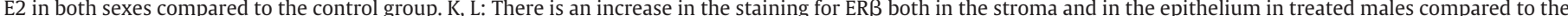

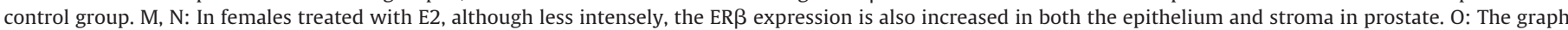

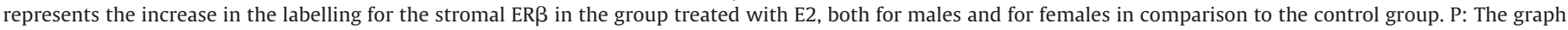

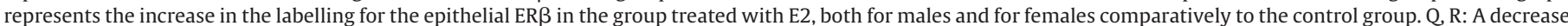

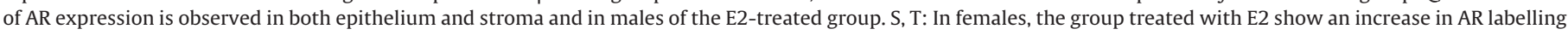

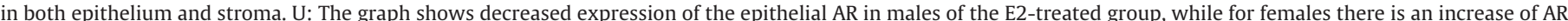

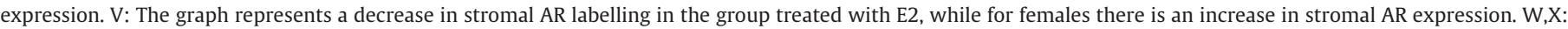

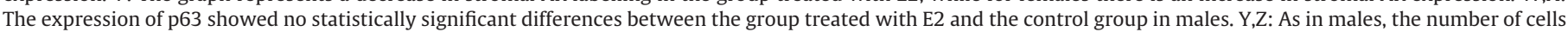

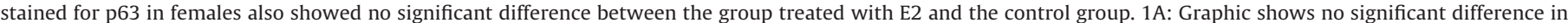

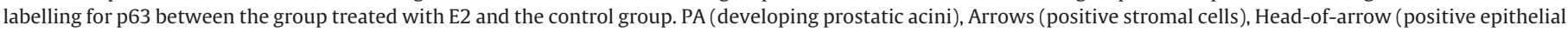
cells), Asterisk (statistically significant difference).

for females there is increased AR staining in both the epithelia and stroma (Figs. $3 \mathrm{Q}, 6$, Table $1 \mathrm{p} \leq 0.05$ ).

\subsection{5. $p 63 P 63$}

The staining of p63 at P14 did not show a statistically significant difference between the group treated with E2 and the control group in both sexes (Figs. 3 U-Y, 6, Table 1, p $\square 0.05$ ).

\subsection{Immunofluorescence assays}

Immunofluorescence assays were performed on paraffinembedded tissue sections of high dose E2 treated gerbils $(500 \mu \mathrm{g}$ BW/D) of both sexes on P14 for the following factors:

\subsection{1. $C D 34 / F G F-10$}

Double immunofluorescence assays for CD34/FGF-10 showed that CD34 labelling is verified in the periductal smooth muscle and in the surrounding stroma in female prostate on P14, while
FGF-10 immunolabelling is verified in the stroma at the periphery of the developing prostatic acini 4(A-D), a different pattern can be observed in females of the E2-treated group ( $500 \mu \mathrm{g} B W / D)$, in which CD34 is verified in the vicinity of prostatic acini in addition to the labelling observed in the periurethral smooth muscle and also in the blood vessels (Fig. 4E-H). In males of the control group at P14, labelling for CD34 is present in blood vessels, and the labelling for FGF-10 is seen in the peripheral region of developing prostatic acini (Fig. 4I-L), as verified in the females, whereas in males in the E2-treated group (500 $\mu \mathrm{g} \mathrm{BW} / \mathrm{D}$ ) at P14, the labelling for CD34, in addition to which is observed in the blood vessels, is also interspersed in the prostatic stroma in the interacinar region, and the labelling for FGF-10 does not completely surround prostatic acini (Fig. 4M-P).

\subsection{2. $C D 34 / T G F \beta 1$}

Double immunofluorescence assays for CD34/TGF $\beta 1$ show that in the females of the control group on P14 it is possible to observe 


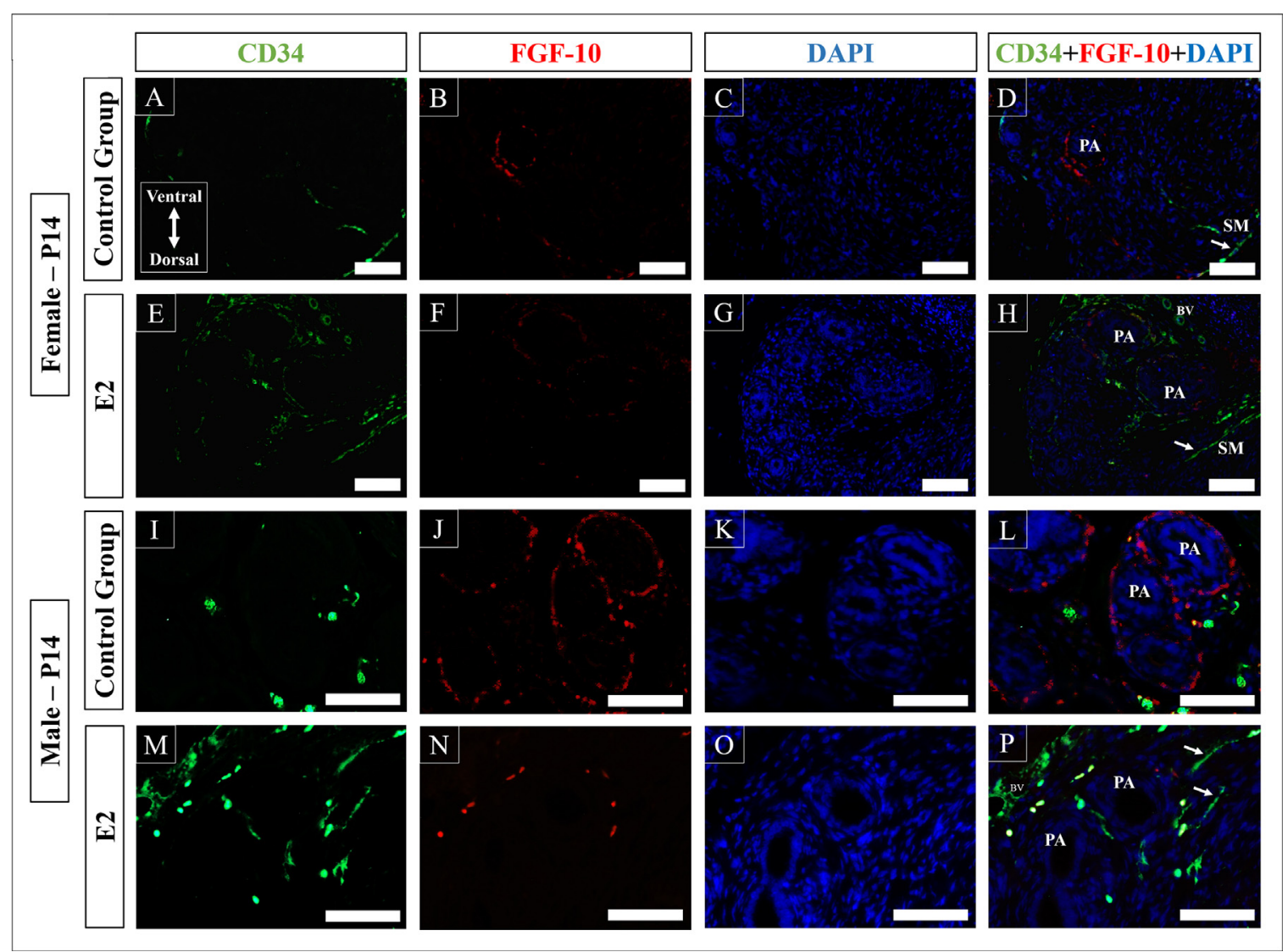

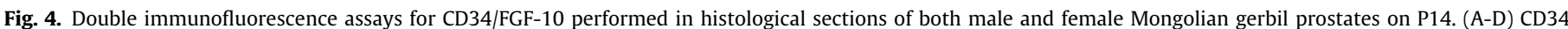

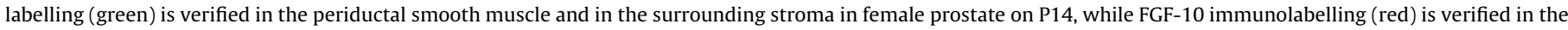

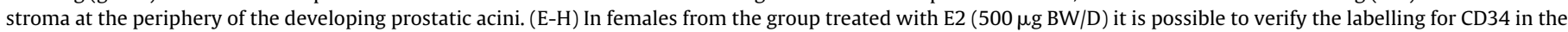

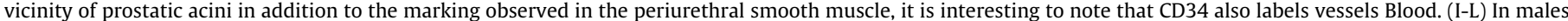

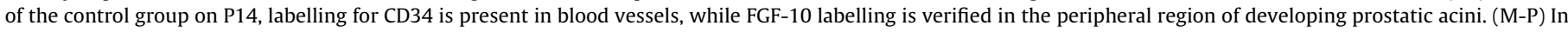

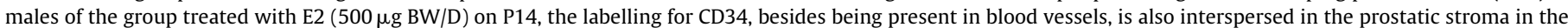

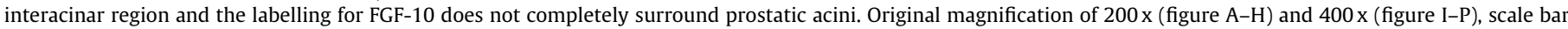

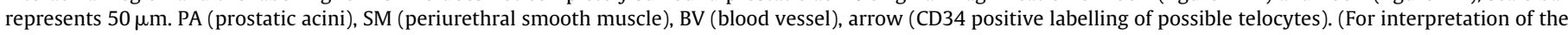
references to colour in this figure legend, the reader is referred to the web version of this article.)

the labelling for CD34 in the blood vessels, in addition to a scattered TGF 31 labelling in the stroma (Fig. 5A-D), as the co-localization of CD34 and TGF 31 of the E2-treated group can be verified in addition to the labelling for CD34 in the blood vessels (Fig. 5E-H). In males of the control group, a similar pattern of immunostaining was observed in females of the control group, with the labelling for CD34 concentrated in the blood vessels and scattered stromal labelling for TGF $\beta 1$ (Fig. 5I-L). In the E2 treated group, it is possible to verify the labelling for $\mathrm{CD} 34$ in the peripheral region of prostatic acini, as well as the colocalization with TGF $\beta 1$ (Fig. 5M-P).

\subsection{Serum hormonal analysis}

Serological data for male and female of young gerbils on P14 showed an increase in oestradiol levels in both the male and female E2 groups $(25.4 \pm 6 \mathrm{pg} / \mathrm{ml}$ and $35.1 \pm 5 \mathrm{pg} / \mathrm{ml}$, respectively) compared to the control group $(19.7 \pm 2 \mathrm{pg} / \mathrm{ml}$ and $25.4 \pm 6 \mathrm{pg} / \mathrm{ml}$, respectively). Values are expressed as mean $\pm S D(n=10)$. Significant differences between the control and E2 groups were verified $(\mathrm{p} \leq 0.05)$ and the serological data confirmed a developmental oestrogenisation during prostate development (Fig. 7).

\section{Discussion}

In addition to increased susceptibility to pathological conditions, which has been associated with intrauterine/perinatal oestrogen exposure in senescence in previous studies $[4,12,22,35,36]$, our study demonstrates the occurrence of structural alterations in the gland which affect the branching process in both sexes during the early postnatal life. Moreover, our structural data demonstrated that a dosage of $500 \mathrm{ng}$. BW/D is able to promote morphological alterations in female prostate development. This is worrying in view of the occurrence of prostates in a proportion of women $[37,38]$, which could make them more susceptible to changes throughout life to environmentally relevant doses of oestradiol, which would not necessarily be detected in the male prostate. This should be considered along with the fact that sewage treatment systems do not ensure the full removal of active oestradiol at the end of treatment and, in addition, soil contamination by oestradiol is still difficult to measure [1,5-7].

Analysis of the three-dimensional structure of prostate in the control group and in the E2 treated group reveals that females exposed to a lower and environmentally relevant dose (500 ng.BW/D) have reduced amounts of prostate branches, as well as changes in the formation of the three-dimensional network of acini and prostatic ducts. These effects are accentuated in the 


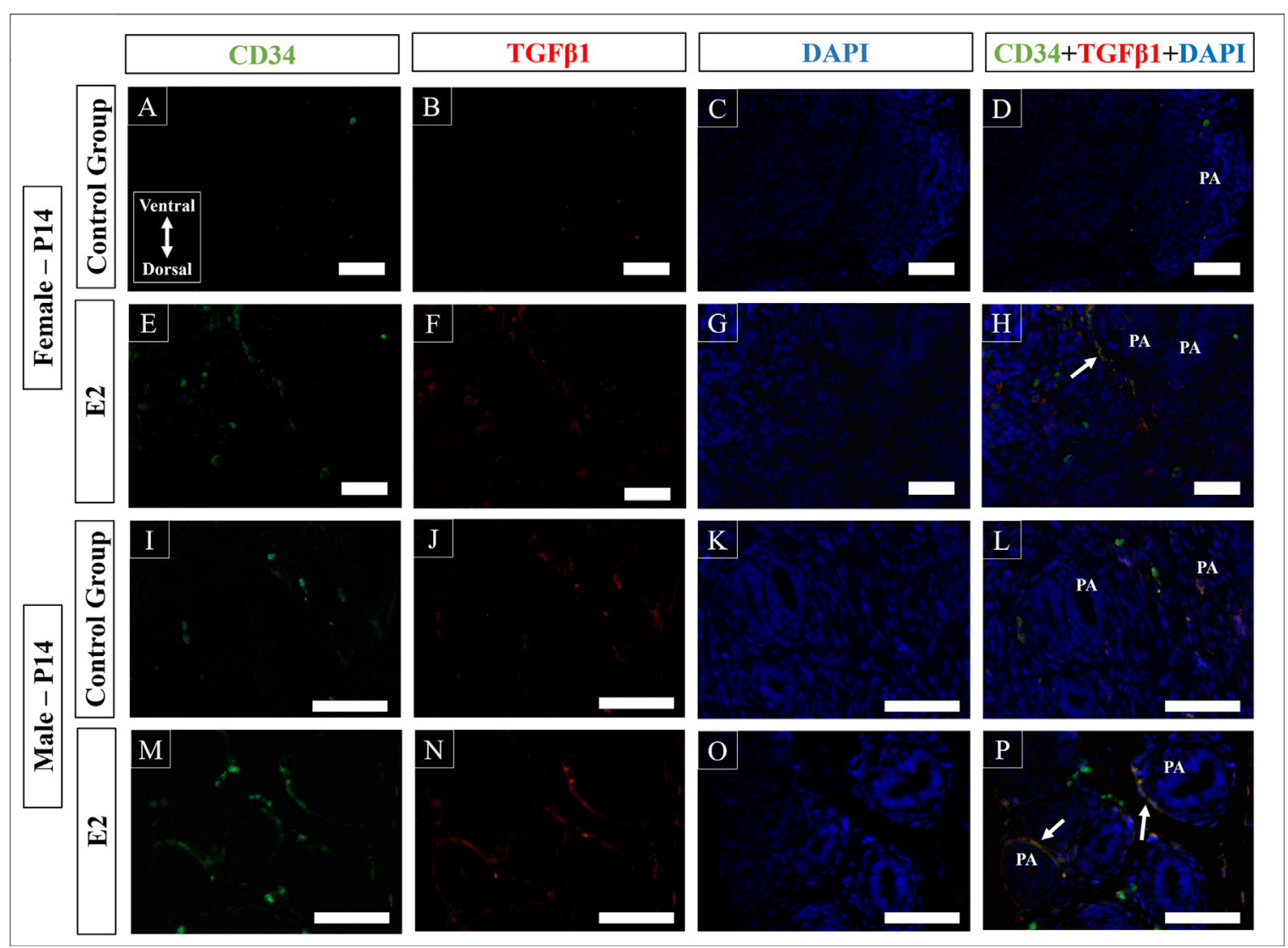

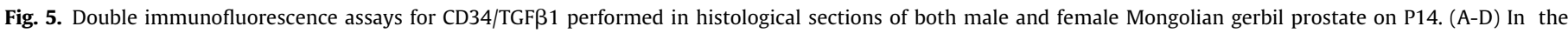

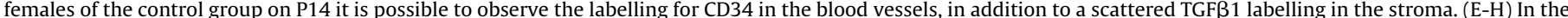

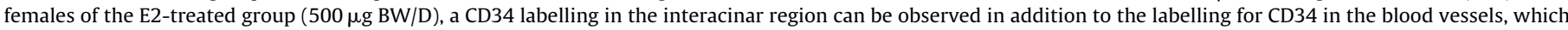

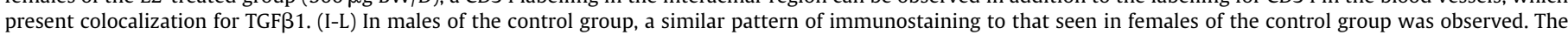

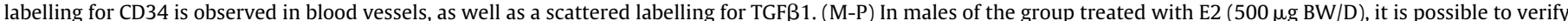

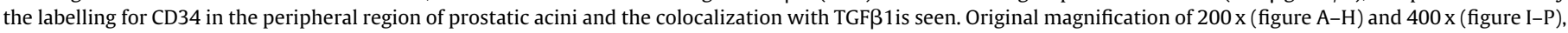
scale bar represents $50 \mu \mathrm{m}$. PA (prostatic acini), SM (periurethral smooth muscle), arrow (fibrillar-like CD34 positive labelling of possible telocytes).

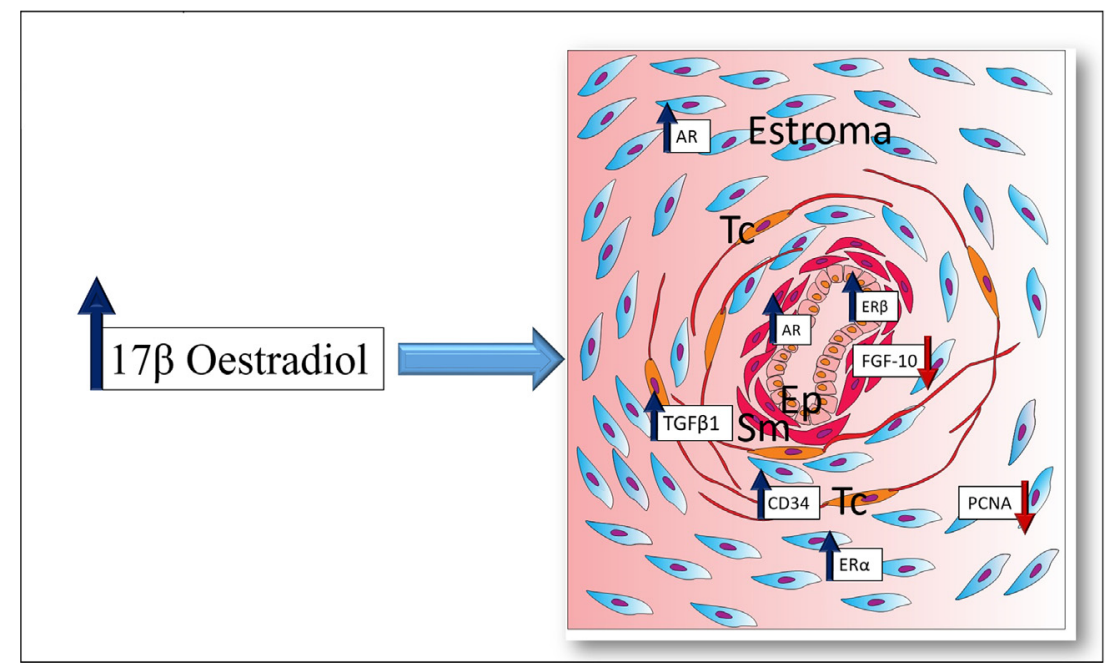

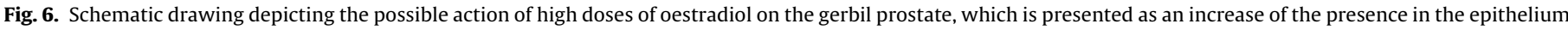

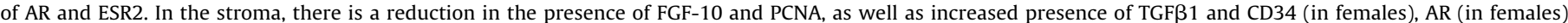

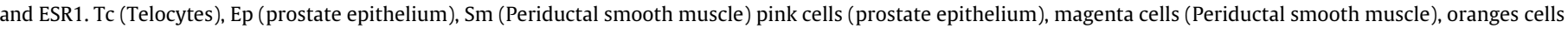
(Telocytes), Blue cells (prostatic stroma). (For interpretation of the references to colour in this figure legend, the reader is referred to the web version of this article.)

gerbil prostate in both sexes submitted to higher dose of oestradiol (500 $\mu \mathrm{g} . \mathrm{BW} / \mathrm{D})$, as previously verified for males of mice [23] and in the human prostate [13]. The prostate gland of females has shown to be more sensitive to intrauterine exposure to E2 in early postnatal development, being affected at a lower dose of E2 (500 ng.BW/D), which is expected due to the role played by oestrogen in the female prostate development, that would be equivalent to that exerted by testosterone through the AR in the development 


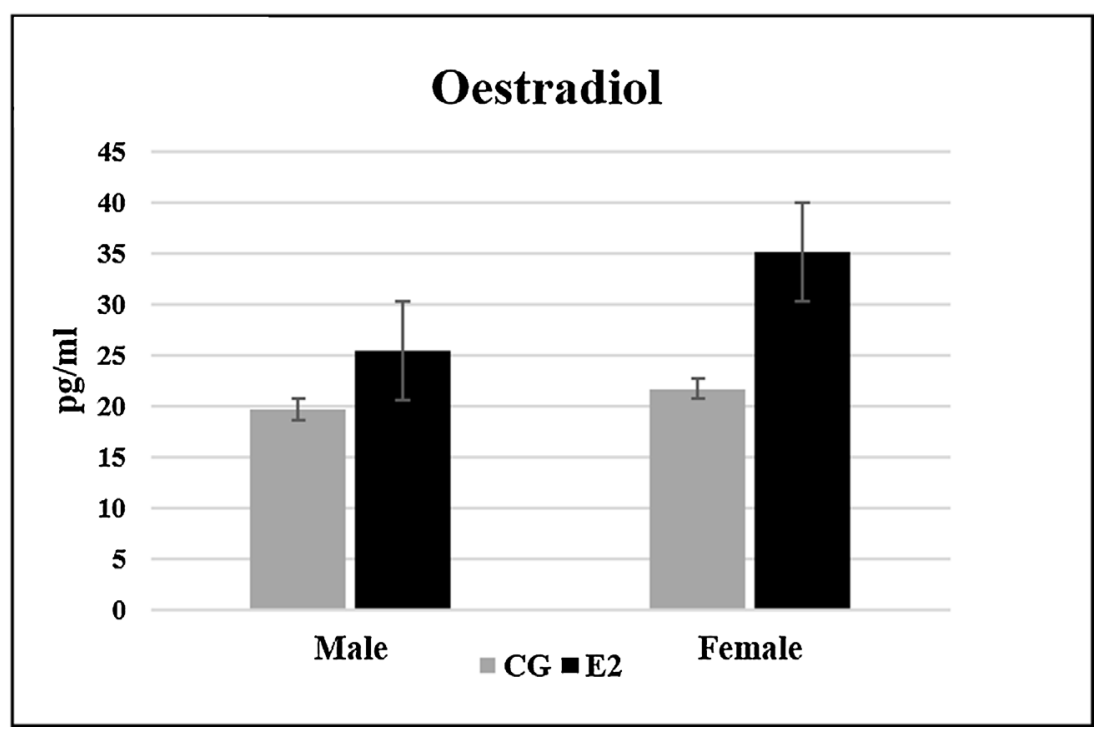

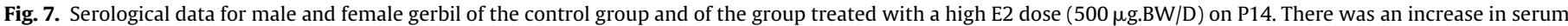

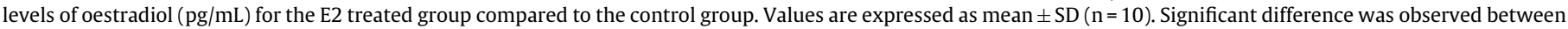
the groups $(\mathrm{p} \leq 0.05)$.

of male prostate, since low testosterone dosages are verified in female serum, along with lower AR expression comparatively to male $[25,27,39]$. Conversely, studies about intrauterine exposure to ethinylestradiol showed more severe effects on maturation and senescence in males than in females [4,22].

While recent studies have given more emphasis on the role of epigenetics on the origin of the increased susceptibility to pathological conditions in the senescence resulting from oestrogen exposure during development, especially in the effect of oestradiol on gene methylation patterns related to prostate development [13,40-43], more direct alterations in prostate development should not be disregarded in view of the fact that prostate grows on a fine control of growth and differentiation factors involved in epithelialmesenchymal interactions which give rise to gland and that such interactions may be changed by intrauterine oestrogen exposure $[44,45]$.

Part of the complexity of oestrogen action on the prostate is related to the existence of two receptors with distinct actions; while $\mathrm{ER} \alpha$ stimulates epithelial cell proliferation, ER $\beta$ stimulate epithelial differentiation and secretory activity, presenting delayed expression in the prostate $[46,47]$. The number of ER $\alpha$ positive cells is increased in both males and females treated with a high dose of E2 (500 $\mu$ g.BW/D), but at the same time ER $\beta$ also shows increased number of positive cells in both sexes, which reflects an imbalance in the standard expression of these receptors. Alteration in oestrogen receptors expression due to high dose perinatal exposure was previously verified for rat male prostate, firstly to ER $\alpha$ [48] and later to ER $\beta$ [49]. The increase of ER $\beta$ stimulates the reduction in epithelial proliferation and promotes epithelial differentiation $[4,39,46]$.

Cell proliferation is reduced in both males and females; additionally, the presence of FGF-10, a factor that promotes epithelial proliferation and prostatic branching morphogenesis [45], is reduced in the periductal region, which could partially justify the occurrence of branching morphogenesis defects [50]. The reduction of the FGF-10 expression due to intrauterine oestrogen exposure was also observed for mice [21,51]. TGF $\beta 1$ labelling is verified at the periphery of prostatic acini in the group treated with a high dose of E2 $(500 \mu \mathrm{g} . \mathrm{BW} / \mathrm{D})$; this result has been previously observed in rats [52]. This factor has an opposite staining pattern to FGF-10 on the prostate in postnatal development, being expressed in the interaci- nar region, while FGF-10 is expressed in the periductal/periacinar region. There are evidences that TGF $\beta 1$ directly inhibits FGF-10, which may explain the inhibitory action of oestradiol on FGF-10 $[45,50]$. However, the role of oestradiol on TGF $\beta 1$ remains controversial, as there are evidences pointing that it may inhibit [53] or promote this factor 52, 54]. TGF $\beta 1$ also acts in smooth muscle differentiation $[55,56]$, this could justify the increase in the diameter of periurethral smooth muscle observed in the E2 treated group in both sexes.

Given the fine coordination in time of the action of growth and differentiation factors involved in prostate development, minimal changes in these factors can be drastic in the development process $[45,57]$. Oestrogen developmental exposure, for example, leads to an increase in stromal TGF $\beta 1$ expression, stimulating the differentiation of smooth muscle [55,56]; albeit this would also lead to a reduction in the expression of TGF $\beta 1$ in prostatic epithelium, retarding the differentiation of epithelial cells [45,52]. In addition, our data point to an increase in the staining of ER $\alpha$ and ER $\beta$, which would simultaneously promote epithelial proliferation and differentiation. The performance of dual factors in this scenario could justify changes to the branching process observed in this work.

In addition, oestrogenisation has a distinct effect on AR expression between males and females; whereas the expression in male decreases, in the female it is increased, previous studies in rats demonstrated only a decrease in AR expression in rats as a result of intrauterine oestrogenization, as in these rodents, female prostate is rare [21]. The AR expression difference between the sexes in the context of oestrogen developmental exposure adds complexity to this field of research. Furthermore, as observed for oestrogen receptors, the AR also acts in a dual manner: epithelial AR promotes the functional differentiation of prostatic epithelia [58,59], while stromal AR promotes epithelial proliferation [60,61]. In this study, both epithelial and stromal androgen receptors showed increased expression in females, generating opposite effects on development, which could explain the higher sensitivity of the female prostate to intrauterine E2 exposure. Given the correlations between development and tumorigenesis $[4,12,22]$, the greater sensitivity of females to alterations in development raises concerns in the face of evidence pointing to the occurrence of tumours of prostatic origin in women [62,63]. 
Finally, our data showed that CD34 positive segments possibly belonging to telocytes are observed in the interacinar region, these segments are also TGF $\beta 1$ positive and the presence of these is increased in the E2 treated group for both sexes. This is interesting in view of the fact that telocytes are a new cell type supposed to be associated in prostate with the gland development [64] and smooth muscle differentiation [18,19]. These findings indicate that oestradiol could act on telocytes populations and such aspect may consist of a new way of oestradiol action on the prostate.

\section{Conclusion}

Our work showed that oestradiol can cause alterations in prostate development in females at relatively small doses, which corroborates the data in the literature that warns of the risk of free oestradiol in the environment. At the same time, this paper showed that high intrauterine doses of estradiol are related to a decrease in cellular proliferation in the prostate, as well as a reduction in the amount of branches and changes in the formation of the threedimensional network of prostatic ducts in both sexes. Such changes in prostatic development may be related to an increase in oestrogen sensitivity (both for ER $\alpha$ and ER $\beta$ ) in both male and female prostates. On the other hand, the greater sensitivity of female prostate to the E2 can be justified considering the greater dependence of such hormone during the development of the gland in females. This becomes alarming in view of the occurrence of functional prostate in female of several species of mammals and also in a portion of women, and the possibility of developmental alterations in female prostate resulting from low E2 dosage exposures that would not generate effects in the male prostate. However, more studies are needed to elucidate the molecular mechanisms underlying the differences between the sexes in susceptibility to changes in prostate development arising from intrauterine exposure to E2.

\section{Contribution of authors}

This study was conducted as a collaboration. All authors (BDAS, JSM, BCZ, MFB, FCAS, RMG, PSLV and SRT) contributed to the design and interpretation of results and review of the manuscript. BDAS, BCZ and JSM performed the experiments. BDAS wrote the manuscript, SRT conducted the final review of the manuscript.

\section{Funding agency}

FAPESP - São Paulo Research Foundation (Grant $\mathrm{Nr}$ 2013/15939-0, 2013/16443-9) and CNPq - National Council of Scientific and Technological Development (Grant Nr 305840/2015-0, 442630/2014-0).

\section{Acknowledgements}

We thank FAPESP for funding, as well as to researchers of Microscopy Microanalysis Laboratory (LMM) for technical support.

\section{References}

[1] S. Combalbert, G. Hernandez-Raquet, Occurrence, fate, and biodegradation of oestrogens in sewage and manure, Appl. Microbiol. Biotechnol. 86 (2010) $1671-1692$

[2] E. Diamanti-Kandarakis, J.-P. Bourguignon, L.C. Giudice, R. Hauser, G.S. Prins, A.M. Soto, T. Zoeller, A.C. Gore, Endocrine-disrupting chemicals: an endocrine society scientific statement, Endocr. Rev. 30 (2009) 293-342.

[3] M.E. Rebuli, H.B. Patisaul, Assessment of sex specific endocrine disrupting effects in the prenatal and pre-pubertal rodent brain, J. Steroid Biochem. Mol. Biol. (2015) 30053-30054, S0960-0760(15).

[4] A.P. Perez, M.F. Biancardi, C.R. Caires, J.R. Falleiros LR, R.M. Góes, F.C. Santos, S.R. Taboga, Pubertal exposure to ethinylestradiol promotes different effects on the morphology of the prostate of the male and female gerbil during aging Environ. Toxicol. 32 (2) (2017) 477-489, http://dx.doi.org/10.1002/tox.22252.

[5] P.D. Anderson, A.C. Johnson, D. Pfeiffer, D.J. Caldwell, R. Hannah, F. Mastrocco, J.P. Sumpter, R.J. Williams, Endocrine disruption due to oestrogens derived from humans predicted to be low in the majority of U.S. surface waters, Environ. Toxicol. Chem. 31 (2012) 1407-1415.

[6] T. Manickum, W. John, Occurrence, fate and environmental risk assessment of endocrine disrupting compounds at the wastewater treatment works in Pietermaritzburg (South Africa), Sci. Total Environ. 468-469 (2014) 584-597.

[7] K.Y. Chen, P.H. Chou, Detection of endocrine active substances in the aquatic environment in southern Taiwan using bioassays and LC-MS/MS, Chemosphere 152 (2016) 214-220.

[8] C.P. Silva, M. Otero, V. Esteves, Processes for the elimination of oestrogenic steroid hormones from water: a review, Environ. Pollut. 165 (2012) 38-58.

[9] S.E. Fenton, C. Reed, R.R. Newbold, Perinatal environmental exposures affect mammary development, function, and cancer risk in adulthood, Annu. Rev. Pharmacol. Toxicol. 52 (2012) 455-479.

[10] G. Delbès, C. Levacher, R. Habert, Oestrogen effects on foetal and neonatal testicular development, Reproduction 132 (2006) 527-538.

[11] R. Santti, R.R. Newbold, S. Mäkelä, L. Pylkkänen, J.A. Mclachlan, Developmental oestrogenisation and prostatic neoplasia, Prostate 24 (1994) 67-78.

[12] G.S. Prins, L. Birch, W.-Y. Tang, S.-M. Ho, Developmental oestrogen exposures predispose to prostate carcinogenesis with aging, Reprod. Toxicol. 23 (2007) 374-382.

[13] C.M. Saffarini, E.V. Mcdonnell-Clark, A. Amin, S.M. Huse, K. Boekelheide, Developmental exposure to oestrogen alters differentiation and epigenetic programming in a human foetal prostate xenograft model, PLoS One 2310 (3) (2015) e0122290.

[14] G.R. Cunha, The role of androgens in the epithelio-mesenchymal interactions involved in prostatic morphogenesis in embryonic mice, Anat. Rec. 1 (1973) 87-96.

[15] B.G. Timms, Prostate development: a historical perspective, Differentiation 76 (2008) 565-577

[16] B.G. Timms, L.E. Hofkamp, Prostate development and growth in benign prostatic hyperplasia, Differentiation 82 (2011) 173-183.

[17] B.D.A. Sanches, M.F. Biancardi, F.C.A. Santos, R.M. Góes, P.S.L. Vilamaior, S.R. Taboga, Budding process during the organogenesis of the ventral prostatic lobe in mongolian gerbil, Microsc. Res. Tech. 77 (2014) 458-466.

[18] B.D.A. Sanches, J.S. Maldarine, B.C. Zani, M.F. Biancardi, F.C.A. Santos, R.M. Góes, P.S.L. Vilamaior, S.R. Taboga, The expression of the androgen receptor and oestrogen receptor 1 is related to sex dimorphism in the gerbil prostate development, Anat. Rec. 299 (2016) 1130-1139.

[19] B.D.A. Sanches, B.C. Zani, J.S. Maldarine, M.F. Biancardi, F.C.A. Santos, R.M. Góes, P.S.L. Vilamaior, S.R. Taboga, Postnatal development of Mongolian gerbil female prostate: an immunohistochemical and 3D modelling study, Microsc. Res. Tech. 79 (2016) 438-446.

[20] G.S. Prins, Neonatal oestrogen exposure induces lobe-specific alterations in adult rat prostate androgen receptor expression, Endocrinology 130 (1992) 3703-3714.

[21] G.S. Prins, L. Huang, L. Birch, Y. e Pu, The role of oestrogens in normal and abnormal development of the prostate gland, Ann. N. Y. Acad. Sci. 1089 (2006) $1-13$.

[22] A.P.S. Perez, M.F. Biancardi, P.S.L. Vilamaior, R.M. Góes, F.C.A. Santos, S.R. Taboga, Microscopic comparative study of the exposure effects of testosterone cypionate and ethinylestradiol during prenatal life on the prostatic tissue of adult gerbils, Microsc. Res. Tech. 75 (2012) 1084-1092.

[23] Y. Pu, L. Huang, G.S. Prins, Sonic Hedgehog-Patched-Gli signalling in the developing rat prostate gland: lobe-specific suppression by neonatal oestrogens reduces ductal growth and branching, Develop Biol. 273 (2004) $257-275$.

[24] F.C. Santos, H.F. Carvalho, R.M. Góes, S.R. Taboga, Structure, histochemistry, and ultrastructure of the epithelium and stroma in the gerbil (Meriones unguiculatus) female prostate, Tissue Cell 35 (2003) 447-457.

[25] A.M. Custódio, R.M. Góes, S.R. Taboga, Acid phosphatase activity in gerbil prostate: comparative study in male and female during postnatal development, Cell Biol. Int. 28 (2004) 335-344.

[26] S.R. Taboga, P.S.L. Vilamaior, R.M. Góes, Androgenic and oestrogenic modulation in the prostate: an approach in rodent experimental models with emphasis on structural biology, Arq. Bras. Endocrinol. Metabol. 53 (2009) 946-955.

[27] A.M.G. Custodio, F.C.A. Santos, S.G.P. Campos, P.S.L. Vilamaior, S.M. Oliveira, R.M. Góes, et al., Disorders related with ageing in the gerbil female prostate (Skene's paraurethral glands), Int. J. Exp. Pathol. 91 (2010) 132-143.

[28] M.F. Biancardi, F.C. Dos Santos, H.F. de Carvalho, B.D. Sanches, S.R. Taboga, Female Prostate: historical, developmental, and morphological perspectives, Cell Biol. Int. (2017), http://dx.doi.org/10.1002/cbin.10759 (Epub ahead of print).

[29] O. Putz, C.B. Schwartz, G.A. LeBlanc, R.L. Cooper, G.S. Prins, Neonatal low- and high-dose exposure to oestradiol benzoate in the male rat: II: Effects on male puberty and the reproductive tract, Biol. Reprod. 65 (2001) 1506-1517.

[30] J.C. Fiala, Reconstruct: a free editor for serial section microscopy, J. Microsc. 218 (2005) 52-61.

[31] R.A. Fochi, F.C. Santos, R.M. Goes, S.R. Taboga, Progesterone as a morphological regulatory factor of the male and female gerbil prostate, Int. J. Exp. Pathol. 94 (2013) 373-386. 
[32] A.A. Renshaw, J.P. Richie, K.R. Loughlin, M. Jiroutek, A. Chung, Maximum diameter of prostatic carcinoma is a simple, inexpensive, and independent predictor of prostate-specific antigen failure in radical prostatectomy specimens. Validation in a cohort of 434 patients, Am. J. Clin. Pathol. 111 (1999) 641-644.

[33] R.F. Lima, D.A. Rodriguez, M.S. Campos, et al., Bisphenol-A promotes antiproliferative effects during neonatal prostate development in male and female gerbils, Reprod. Toxicol. 58 (2015) 238-245.

[35] W.R. Scarano, D.E. Sousa, S.G. Campos, L.S. Corradi, O.S. Vilamaior, S.R. Taboga, Oestrogen supplementation following castration promotes stromal remodelling and histopathological alterations in the Mongolian gerbil ventral prostate, Int. J. Exp. Pathol. 89 (2008) 25-37.

[36] L.S. Corradi, S.G. Campos, F.C. Santos, P.S. Vilamaior, R.M.E. Góes, S.R. Taboga, Long-term inhibition of 5-alpha reductase and aromatase changes the cellular and extracellular compartments in gerbil ventral prostate at different postnatal ages, Int. J. Exp. Pathol. 90 (2009) 79-94.

[37] N. Wernert, M. Albrech, I. Sesterhenn, R. Goebbels, H. Bonkhoff, G. Seitz, R. Inniger, K. Remberger, The 'female prostate': location, morphology, immunohistochemical characteristics and significance, Eur Urol. 22 (1992) 64-69.

[38] W. Dietrich, M. Susani, L. Stifter, A. Haitel, The human female prostate immunohistochemical study with prostate-specific antigen, prostate-specific alkaline phosphatase, and androgen receptor and 3-D remodelling, J Sex Med. 8 (2011) 2816-2821.

[39] S.S. Rochel-Maia, F.C.A. Santos, P. Alonso-Magdalena, R.M. Góes, P.S.L. Vilamaior, M. Warner, J.-A. Gustafsson, S.R. Taboga, Oestrogen receptors alpha and beta in male and female gerbil prostates, Biol. Reprod. 88 (2013) 1-7.

[40] S.-M. Ho, W.-Y. Tang, J.B. De Frausto, G.S. Prins, Developmental exposure to oestradiol and bisphenol A increases susceptibility to prostate carcinogenesis and epigenetically regulates phosphodiesterase type 4 variant 4 , Cancer Res. 66 (2006) 5624-5632.

[41] M.K. Skinner, M. Manikkam, C. Guerrero-Bosagna, Epigenetic transgenerational actions of endocrine disruptors, Reprod. Toxicol. 31 (2011) 337-343.

[42] F. Perera, J. Herbstman, Prenatal environmental exposures, epigenetics, and disease, Reprod. Toxicol. 31 (2011) 363-373.

[43] W.Y. Tang, L.M. Morey, Y.Y. Cheung, L. Birch, G.S. Prins, S.M. Ho, Neonatal exposure to oestradiol/bisphenol A alters promoter methylation and expression of Nsbp1 and Hpcal1 genes and transcriptional programs of Dnmt3a/b and Mbd2/4 in the rat prostate gland throughout life, Endocrinology 153 (2012) 42-55.

[44] G.S. Prins, L. Birch, H. Habermann, W.Y. Chang, C. Tebeau, O. Putz, C. Bieberich, Influence of neonatal oestrogens on rat prostate development, Reprod. Fertil. Dev. 13 (2001) 241-252.

[45] G.S. Prins, O. Putz, Molecular signalling pathways that regulate prostate gland development, Differentiation 76 (2008) 641-659.

[46] S.J. Ellem, G.P. Risbridger, The dual, opposing roles of oestrogen in the prostate, Ann. N. Y. Acad. Sci. Steroid Enzymes Cancer 1155 (2009) 174-186.

[47] I. Takizawa, M.G. Lawrence, P. Balanathan, R. Rebello, H.B. Pearson, E. Garg, L. Furic, Oestrogen receptor alpha drives proliferation in PTEN-deficient prostate carcinoma by stimulating survival signalling, MYC expression and altering glucose sensitivity, Oncotarget 6 (2015) 604-616.

[48] G.S. Prins, L. Birch, Neonatal estrogen exposure up-regulates estrogen receptor expression in the developing and adult rat prostate lobes, Endocrinology 138 (5) (1997) 1801-1809.
[49] G.S. Prins, M. Marmer, C. Woodham, W. Chang, G. Kuiper, J.A. Gustafsson, L. Birch, Estrogen receptor-beta messenger ribonucleic acid ontogeny in the prostate of normal and neonatally estrogenized rats, Endocrinology 139 (3) (1998) 874-883.

[50] D.C. Tomlinson, J.C. Grindley, A.A. Thomson, Regulation of Fgf10 gene expression in the prostate: identification of transforming growth factor-beta and promoter elements, Endocrinology 145 (2004) 1988-1995.

[51] L. Huang, Y. Pu, S. Alam, L. Birch, G.S. Prins, The role of Fgf10 signaling in branching morphogenesis and gene expression of the rat prostate gland: lobe-specific suppression by neonatal estrogens, Dev. Biol. 278 (2) (2005) 396-414.

[52] W.Y. Chang, L. Birch, C. Woodham, L.I. Gold, G.S. Prins, Neonatal oestrogen exposure alters the transforming growth factor-beta signalling system in the developing rat prostate and blocks the transient p21(cip1/waf1) expression associated with epithelial differentiation, Endocrinology 140 (1999) 2801-2813.

[53] B. Kleuser, D. Malek, R. Gust, H.H. Pertz, H. Potteck, 17-Beta-oestradiol inhibits transforming growth factor-beta signalling and function in breast cancer cells via activation of extracellular signal-regulated kinase through the $G$ protein-coupled receptor 30, Mol. Pharmacol. 74 (2008) 1533-1543.

[55] J.H. Hong C. Song, Y. Shin, H. Kim, S.P. Cho, W.J. Kim, H. Ahn, Oestrogen induction of smooth muscle differentiation of human prostatic stromal cells is mediated by transforming growth factor-beta, J. Urol. 171 (2004) 1965-1969.

[56] X. Guo, S.Y. Chen, Transforming growth factor- $\beta$ and smooth muscle differentiation, World J. Biol. Chem. 3 (2012) 41-52.

[57] J.D. Wilson, The critical role of androgens in prostate development, Endocrinol. Metab. Clin. North Am. 40 (2011) 577-590.

[58] G.R. Cunha, P. Young, Inability of Tfm (testicular feminisation) epithelial cells to express androgen-dependent seminal vesicle secretory proteins in chimeric tissue recombinants, Endocrinology 128 (1991) 3293-3298.

[59] K.M. McNamara, Y. Nakamura, H. Sasano, D.J. Handelsman, U. Simanainen, Prostate epithelial AR inactivation leads to increased intraprostatic androgen synthesis, Prostate 73 (2013) 316-327.

[60] P.S. Cooke, P. Young, G.R. Cunha, Androgen receptor expression in developing male reproductive organs, Endocrinology 128 (1991) 2867-2873.

[61] M. Singh, R. Jha, J. Melamed, E. Shapiro, S.W. Hayward, P. Lee, Stromal androgen receptor in prostate development and cancer, Am. J. Pathol. 184 (2014) 2598-2607.

[62] S.T. Reis, J. Pontes-Júnior, A.A. Antunes, J.M. Sousa-Canavez, D.K. Abe, J.A. Cruz M.F. Dall'oglio, A. Crippa, C.C. Passerotti, L.A. Ribeiro-Filho, N.I. Viana, M. Srougi, K.R. Leite, Tgf- $\beta 1$ expression as a biomarker of poor prognosis in prostate cancer, Clinics (Sao Paulo). 66 (7) (2011) 1143-1147.

[63] A.L. Pongtippan, A. Malpica, C. Levenback, M.T. Deavers, E.G. Silva, Skene's gland adenocarcinoma resembling prostatic adenocarcinoma, Int. J. Gynecol. Pathol. 23 (January (1)) (2004) 71-74.

[64] L.S. Corradi, M.M. Jesus, R.A. Fochi, P.S.L. Vilamaior, L.A. Justulin, R.M. Góes, S.R. Taboga, Structural and ultrastructural evidence for telocytes in prostate stroma, J. Cell. Mol. Med. 17 (2013) 398-406.

[65] B.D. Sanches, L.S. Corradi, P.S. Vilamaior, S.R. Taboga, Paracrine signaling in the prostatic stroma: a novel role for the telocytes revealed in rodents' ventral prostate, Adv. Exp. Med. Biol. 913 (2016) 193-206. 